\title{
Supporting EFL Learners' Reflective Practices through Systemic Functional Linguistic Praxis: A Longitudinal Case Study*
}

\author{
Xiaodong Zhang ${ }^{1}$ \\ Beijing Foreign Studies University
}

\begin{abstract}
This study reports how teaching using a systemic functional linguistics (SFL)-based appraisal system impacted English-as- a-foreign-language (EFL) students' reflective practices with text deconstruction and construction. Through qualitative content and discourse analyses of three focal EFL students' reading and writing performance, interviews, and reflection journals collected from two writing classrooms (expository and argumentative writing) in a Chinese university over one academic year, this case study shows that students transformed into reflective learners who could understand and critically deconstruct and construct the relationships among context, interpersonal meaning, and linguistic resources in reading and writing, although their development proceeded in a tortuous process, with writing being slower than reading. Despite this complexity, the study illustrates the malleability of using an SFL-based appraisal system in guiding EFL students to be reflective learners.
\end{abstract}

\section{Keywords}

Reflective practices $\bullet$ Appraisal system $\bullet$ Interpersonal meaning $\bullet$ EFL learning $\bullet$ Reading and writing

\footnotetext{
* The preparation of this paper was supported in part by National Social Science Foundation of China (17CYY019).

1 Correspondence to: Xiaodong Zhang (PhD), School of English and International Studies, Beijing Foreign Studies University, China. Email: zxdman588@gmail.com

Citation: Zhang, X. (2018). Supporting EFL learners' reflective practices through systemic functional linguistic praxis: A longitudinal case study. Educational Sciences: Theory \& Practice, 18, 495-513. http://dx.doi.org/10.12738/estp.2018.2.0022
} 
Reflection is "active, persistent, and careful consideration of any belief or supposed form of knowledge in the light of the grounds that support it and the further conclusion to which it tends" (Dewey, 1933, p. 9). Scholars (e.g., Russell, 2005) have extended the pedagogical power of reflection by emphasizing the inter-relationship between participants' reflection development and constant engagement in reflective practices. Through reflective practices, learners align with new learning beliefs that enable them to analyze or construct effective academic discourse (Larrivee, 2000; Russell, 2005). This is, however, an obviously complex and tortuous process that would not occur in a smooth way without teacher mediation (Hasan, 2005). Indeed, developing reflective practices involves learners renewing their taken-for-granted understanding, solidifying their new knowledge by constantly engaging in discovering issues, reflecting upon their existing issues, and enacting corresponding changes to improve the situation they are in. In the English- as- a- foreign- language (EFL) classroom, this means that, with teacher mediation, students endeavor to challenge the previous learning models they are trapped in, gain a new understanding of academic literacy, and unpack or compose texts as expected in our globalized English language communities, where language users are expected to display knowledge in constructing/deconstructing texts on both language form and meaning levels (Harman, 2017; Zhang, 2017).

Unfortunately, because of constrained teaching (e.g., language form-based teaching at the syntactic level) in EFL contexts, students are often exposed to rule-based grammar knowledge and lack effective knowledge needed for being reflective learners (Zhang, 2017). In addition, one crucial component of enabling EFL students to navigate academic literacy as reflective learners involves their understanding and utilization of interpersonal meaning (i.e., how specific language resources manifest discourse participants' evaluative stances or their way of interacting with an audience) in reading and writing, respectively (Harman \& Simmons, 2014). Indeed, interpersonal meaning is embedded in language communication that reflects how social factors (e.g., power relationships, interactional strategies) impact all discourses, even scientific discourses that are traditionally thought to be free of authors' emotional sentiments (Symons, Palincsar, \& Schleppegrell, 2017). Despite this, explicit teaching of interpersonal meaning seems to be muffled in EFL contexts, which might be a result of a lack of effective teacher education support (Zhang, 2017). As a result, EFL students often lack a pertinent understanding of this and also fail to practice it appropriately, as expected in discourse communication (Yasuda, 2017).

\section{SFL-based Appraisal System on Interpersonal Meaning}

Relevant to the focus of the current study on interpersonal meaning and reflective practices, systemic functional linguistics (SFL) explains, through its appraisal system, how a text author negotiates information, interacts with a potential audience, 
or projects evaluative stances, putting an emphasis on the inter-relationship between meaning and context (Martin \& White, 2003). More importantly, the appraisal system provides categories for understanding how to achieve the meaning through contextually appropriate linguistic resources (i.e., lexicon and grammar). In other words, unlike traditional grammar, which focuses on syntactic accuracy, the appraisal system unpacks interpersonal meaning by highlighting the triadic interaction among context, meaning, and lexico-grammatical choices, making it potentially useful in offering students the multi-layered constructs needed for engaging in reflective practices regarding both language form and meaning. Specifically, the appraisal system, through the three categories of attitude, graduation, and engagement, unravels the myth of interpersonal meaning by explicitly showing the relationship between implicit or explicit linguistic resources and contextual sentiment-such as power relationships or solidarity/disalignment among discourse participants, from discourse authors themselves to readers or listeners or to other participants (e.g., multiple figures within a novel)—within a discourse (Harman \& Simmons, 2014).

In particular, attitude highlights how lexico-grammatical resources project the emotions of discourse participants (e.g., happy, sad), judgment of social behaviors (e.g., brave), or evaluation of inanimate entities (e.g., important). With this construct, students may be guided in recognizing adjectives explicitly used (explicit attitude) in narrative or in the claims of argumentative writing or verbs/adverbs more implicitly used (implicit attitude) when presenting the claims of expository writing or in the process of demonstrating and interpreting evidence in either expository or argumentative writing (Schleppegrell, 2001).

Engagement is related to students' understanding and practices in terms of text authors' embracement of external information and their strategies in molding the certainty of information. The first dimension of engagement dichotomizes interpersonal meaning into monogloss (facts that refuse to open up to different voices), such as the earth is round, and heterogloss (statements that entertain alternative voices), such as John said the earth is round. The second dimension of engagement constrains information through the use of lexical choices in softening the tone, such as modal verbs (e.g., may), adverbs (e.g., usually), or determiners (e.g., some). In this sense, teaching engagement and linguistic manifestation could enable students to understand and practice how information is arranged from external voice to the author's own voice while maintaining the purpose and reliability/credibility of a text type. For instance, expository writing and argumentative writing might use external sources or modal verbs to show evidence or maintain information objectivity, respectively (Schleppegrell, 2001).

Graduation concerns the intensity (e.g., really, kind of) or typicality of information delivered (e.g., kind of) in discourse. For example, when evidence is ample enough, writers 
could say: The evidence obviously illustrates... This category and its related resources could be used to help students become aware of and control the interpersonal meaning that can be either intensified or made typical in the process of discourse negotiation.

Despite the importance of reflective practice and its promising compatibility with the appraisal system for language classroom teaching, a combination of the two has been underexplored in EFL contexts. One likely factor for this is that, as mentioned, many EFL teachers lack SFL-based teacher education. Among the limited studies in the context of English as a second language (ESL) at the pre-college level, which are marginally related to the current research, O'Hallaron, Palincsar, and Schleppegrell (2015) investigated U.S. elementary English language teachers' use of an appraisal system with ESL students and found that students' appropriation of an appraisal system empowered them to decode hidden interpersonal meaning in informational texts, such as science reports. For instance, students identified the text author's use of the adverb fortunately when talking about how there have not been too many serious earthquakes in Michigan, and they became aware of the text author's strategic infusion of opinion into a science report. In a more recent case study, O'Hallaron and Schleppegrell (2016) found that explicit instruction of engagement resources also facilitated U.S. elementary students' argumentative writing performance. For example, students learned how to bring in counter-arguments by showing external voices (some may say that...) or how to carefully use modality in molding supporting details based on their calibration of the certainty of evidence available (e.g., maybe, might). In the EFL context, among the few studies on teaching appraisal systems to EFL students, Yasuda (2017) explored students' interaction with the SFL-based interpersonal perspective in summary writing. By tracking EFL biology major students' progress in a semester-long college writing course in Japan, Yasuda found that students transitioned themselves from a dim awareness of audience to genre-based awareness in which students could use reporting verbs (e.g., the author says/describes) to show the interaction among readers, the author of a source, and themselves during these complex dialogistic activities.

As seen above, while the current literature regarding the use of an appraisal system has been conducted in ESL or EFL contexts, these studies emphasized the impact on students' performance outcomes (e.g., students' final writing products) or teacherstudent interaction. There is still limited research on investigating the compatibility of an SFL-based appraisal system with a reflective practice-based curriculum, especially in a tertiary EFL context (where reflective practices are needed but not implemented), despite the compatibility between appraisal systems and reflective practices. In addition, even among the literature that explored the relationship between appraisal systems and students' reflective practices (e.g., O'Hallaron \& Schleppegrell, 2016), we still lack a clear understanding of students' detailed interaction with the SFL-based pedagogy (e.g., their emotional reaction). Indeed, as Harklau (2000) noted, students' socialization 
(e.g., their cognitive, emotional, and epistemic adoption) into a new curriculum could be complex and might involve dis-alignment, as also echoed by the content of reflective practices that involve a chain of students' efforts in questioning, digesting, probing into facts/assumptions, navigating, or even withdrawing from academic discourse (Hasan, 2005; Larrivee, 2000). To capture the nuanced details of implementing an appraisal-based pedagogy and fill the research gap in the use of appraisal systems in developing EFL students' reflective practices, the present one-year study was guided by the following research question: How does appraisal system-based teaching impact college EFL students' reflective practices (including reflective understanding and relevant practices), if at all? This research seeks to cast light on curriculum innovation and contribute to teaching tools for developing EFL students' reflective practices.

\section{Method}

\section{Research Context}

This study was derived from a larger longitudinal study on using SFL to support college students' academic literacy development. Nineteen students who were learning English as their major in an urban university in China first took an expository writing course where the researcher of this project served as the instructor; following the completion of the course, eight of those students enrolled into an argumentative writing course with the same instructor. Prior to this year-long project, the students were all surveyed upon their first encounter with the researcher (including everyone from the expository writing course and some of those in the argumentative course). The survey showed that the students had been exposed to an English language teaching curriculum that was focused on language accuracy, which has been echoed by existing research on the circumstances in China and in the larger EFL context (e.g., Yasuda, 2017; Zhang, 2017). For example, as illustrated in the survey, literacy practices were focused on writing grammatically correct sentences or decoding complex structure in texts. In other words, these students, similar to many other EFL students, lacked sufficient skills in engaging in effective reflective practices as language learners. Based on years of research experience in the context of ESL, where students became analytic or critical through exposure to SFL praxis, the researcher decided to enact a similar curriculum in the writing courses detailed above.

\section{The SFL Teaching Curriculum in the Writing Classroom}

The SFL-based curriculum included the following components. First, each week, students were given reading materials (e.g., an introduction to SFL or the appraisal system) and an assignment of writing reflection journals based on the readings. The materials assigned to students were essentially the same each semester, except that sample texts changed according to the teaching content - the first half of the academic 
year focused on expository texts, while the second half featured argumentative texts. Second, in class, the teacher mediated students' understanding of meta-linguistic knowledge, deconstruction of reading texts, and composition writing. All texts selected in class were checked and rated by two English language experts, both of whom gave a high score on the appropriateness of the text type, as well language resources. Out of class, students conducted independent deconstructions of new excerpts of the same texts biweekly, which was followed by their reflection on the experience (e.g., their understanding of the link between reading knowledge and writing practices). Third, students wrote an essay monthly. Following completion of the essay, students' writing was first read by their classmates, who provided written feedback. Then, the instructor verified or negated peer feedback and provided further feedback through a written channel, followed by two hour-long verbal feedback responses for one paper (at least). Over the academic year, students wrote three papers in the argumentative writing course (each around 1000 words excluding references) and four papers in the expository course (each around 500 words excluding references).

The purpose of this curriculum, as emphasized by O'Hallaron and Schleppegrell (2016), is to offer students linguistic knowledge and emancipate them from de-contextualized or passive learning, transitioning them into reflective discourse composers and interpreters.

\section{Participants}

All students in the expository and argumentative courses consented to join this project before and after their final grades were posted. This made the research project ethically acceptable. For a longitudinal case study, students who took both expository and argumentative writing with the researcher were selected. To further explore appraisal system-based teaching, three female students were selected among those willing to be tracked over one academic year. The three students were not dissimilar to other students who have limited and de-contextualized understanding of reading and writing literacy, thus representing the classes as a whole, as well the majority of EFL students. That is, they had a good understanding of English discourses at the grammar level but lacked skills in effectively engaging in constructing or deconstructing discourse content. Most importantly, the three students also felt comfortable sharing their artifacts, which could further illuminate their development of reflective practices as EFL learners. These three students were pseudonymously named Min, Pin, and Tin. They were all born and raised in China, speaking Chinese as their first language and English as their second language.

\section{Data Collection and Analysis}

Multiple sources of data were collected over two semesters - first in the expository writing course and then in the argumentative writing course. Data included students' 
reflections, monthly interviews, and written pieces over one academic year, as well as the researcher's field notes. Students' reflections (RE) occurred roughly weekly in both expository writing and argumentative writing and were based on students' reading of SFL-related materials (such as introductory articles on SFL) and their experience in deconstructing or constructing expository writing and argumentative texts. Reflections were written in either the students' first language or English, depending on student preference. Interviews (IE) were conducted in the students' first language (i.e., Chinese) monthly before and after face-to-face tutoring sessions, where students discussed their writing with the researcher. By the end of each semester, students were further interviewed in terms of their overall experience with the curriculum. In the process of data analysis, additional clarifying interviews were also conducted. Complementing the reflection journals, the interviews were utilized to elicit students' experience in the SFL-based curriculum, aimed at unearthing possible changes in students' understanding of academic literacy. Included in the students' written pieces collected for illuminating their changed practices were four essays from expository writing and three from argumentative writing, along with independent reading-based analytic work over the academic year. It must be noted that, while students' essay writing was also mediated by their peer classmates, including written feedback, the excerpts selected for illustrating students' writing practices were those that were mainly improved through their instructor's implicit written and verbal feedback relating to the appraisal system, since the study was focused on the relationship between the teacher's role, the appraisal system, and students' reflective practices. Over the year, the researcher, as the instructor, also took field notes.

Data analysis was primarily informed by qualitative inductive schemes (AttrideStirling, 2001). To show students' reflective understanding, the transcription of field notes, students' interviews, and reflection journals in the original language were subject to rounds of reading between the researcher and another experienced qualitative researcher, followed by condensing and comparing interviews, reflection transcriptions, and field notes in order to unearth themes, ensuring the internal and external validity of this research study (Attride-Stirling, 2001). In particular, in order to facilitate theme retrieval, this inductive process was also infused with initial codes derived from the theoretical framework, such as students' battling with their prior knowledge or students' efforts in this new curriculum, as well as the categories of the appraisal system. The non-English excerpts were later translated by the researcher into English when presenting research findings. To show how students practice interpersonal meaning, students' analytic work and writing artifacts were subject to a broad thematic analysis before representative samples were selected to illustrate pertinent inquiry. Sample segments (either readingbased analytic work or essays) were further evaluated through discourse analysis (Martin \& White, 2003), revealing how the interpersonal meaning in relation to the appraisal system interacted with students' practices on a continuum of reading and writing. 
While separate datasets were used to illustrate the development of students' reflective practices (their reflective understanding and literacy practices) for the sake of convenient readership, the two components were actually interrelated on a continuum. As such, in the findings section of this paper, it could be noted that there are places where findings on students' actual literacy performance and reflective understanding were holistically presented.

\section{Findings}

Overall, EFL students' reflective practices over the academic year turned out to be complex, while still progressing. Through teacher mediation, students strenuously overcame multiple constraints (e.g., difficulty in connecting knowledge with practices, their previous rule-based language learning) before they became reflective learners at the interpersonal level in both the expository writing and argumentative writing courses.

\section{Reflective Journey to Understanding Interpersonal Meaning} Limited understanding of interpersonal meaning due to prior education. Students' initial perception of interpersonal meaning barely existed. Their inactive understanding of interpersonal meaning as EFL learners was particularly demonstrated at the beginning of the year of study during the semester of expository writing. They possessed dim or inappropriate awareness of interacting with their readers in the capacity of a writer. They also primarily relied on their intuition in decoding interpersonal meaning as readers.

Min: Writing is about conveying our meaning to the readers, [...] so we have to have a good vocabulary along with grammar knowledge and negotiate with readers. (RE1)

Pin: I could not help talking to myself and writing complex information that is not understandable. [...] I was so obsessed with writing to myself. (RE2)

Tin: For reading, [...] I basically relied on my conceptual comprehension. [...] I was only taught to understand/focus on vocabulary or grammar. (IE1)

Apparently, while reading and writing are two interrelated and crucial learning sources, previous education on form accuracy (mostly at the syntactic level) in the process of writing or reading had constrained students' knowledge base, which occurs in many EFL contexts (e.g., Zhang, 2017), and failed to engage them in critically understanding discourse at the level of both language form and meaning.

At the same time, the students' reactions to the reflective practice-based teaching progressed in a passive way. This particularly occurred at the beginning of the first half of the academic year, during the expository writing course. 
Min: At the very beginning of the first semester, I did [the relevant activities] because it was a part of an assignment. [...] I did not try hard or understand the content. (RE3)

Pin: My initial attempts were out of my habits of carefully following my instructor's advice, and I did not experience the usefulness immediately. (IE2)

In other words, students' initial participation in the SFL-based curriculum was out of the obligation of being a student (i.e., they tried to do what they were asked to do), although they did not demonstrate explicit or strong resistance. This could be because they had never experienced this new pedagogy and lacked the motivation to challenge themselves in a new context as college English students (Harklau, 2000; Zhang, 2017).

Increasing but unbalanced understanding at the interpersonal level. During their ongoing journeys (in the middle of the first semester and in the second semester), the students gained a gradual understanding about interpersonal meaning and started to show their willingness to construct new selves as writers and readers. In addition, while reading and writing was simultaneously taught in line with the appraisal system and SFL's perspective, it was also noted that the students' acceptance of the curriculum was hampered by their difficulties in connecting this curriculum with writing practices. This occurred both in the middle of expository writing and in the argumentative writing course.

Tin: My previous teacher did not tell me how to analyze the emotions of text authors. [...] I just relied on my intuition. [...] The elaboration of interpersonal meaning with the analytic frame helped me clarify my muddy world [when reading expository texts]. (IE3)

Pin: It started to look useful to me [for decomposing argumentative texts]. [...] But I feel the knowledge cannot be effectively applied to writing, $[\ldots]$ and I just could not see the relationship. (RE4)

Obviously, students demonstrated the bud of reflective identity as a result of increased exposure to the curriculum, but their reflective understanding did not proceed without hurdles. Instead, students' reflective understanding was manifested more in students' reader identities, renewing their cognition or epistemic beliefs about reading. In contrast, students seemed slower in relating writing to the appraisal system, which made them anxious. This could be because learners' appropriation of knowledge deconstruction as readers is generally paced faster than text construction as writers (e.g., Stotsky, 1983).

Students' own efforts in developing reflective understanding. The students' frustration - mostly due to their immature understanding of writing - started to wane as they gained more knowledge and exerted more effort to challenge themselves to understand interpersonal meaning in both reading and writing. This prompted them to resume their alignment with the SFL-based appraisal curriculum, which occurred in both expository and argumentative writing. 
Min: I feel I could better carve into the academic texts because I am getting familiar with the appraisal system. [...] I do need to challenge myself. [...] Being a reflective writer or reader seems cool and important, as [the researcher] said and encouraged. (IE4)

Pin: We need to be reflective in this classroom. [...] The ambience is there. [...] I am not sure what will happen to me, [...] but I think it would be better to learn content available well and be a better self. (RE5)

In other words, the students became less anxious with their gradual increase in understanding of the knowledge embedded in the curriculum and awareness of the importance of being a reflective reader/writer (Bayat, 2014; Larrivee, 2000). As such, the students started to become more invested in renewing their knowledge of interpersonal meaning in conjunction with the appraisal system, thus reconceptualizing expository and argumentative writing.

\section{Emerging obstacles to ongoing development of reflective understanding.} Despite the emerging and promising passion of the students' acceptance of the appraisal system, the process of their reflection and understanding turned out to be unexpectedly complex and characterized by relapse, doubt, and frustration. This happened in the middle of both expository and argumentative writing.

Tin: I could not well understand engagement, graduation, and attitude. I just could not differentiate them. $[\ldots]$ These resources $[\ldots]$ seem hard to understand in certain contexts. (RE6)

Min: Am I mechanically using them? [...] I feel like I am learning rules and applied to do this as instructed. [...] Or am I really analyzing? [...] I feel frustrated. I am most of the time imitating [...], not thinking actively. (IE5)

Thus, following a short session of honeymoon learning, students' reflective processes were disrupted. Students' resistance or negative sentiment seemed to arise out of the complexity of the appraisal system, especially given that they had never encountered linguistic knowledge before (Macken-Horarik, Love, \& Unsworth, 2011).

Further adaptation due to teacher mediation and hands-on activities. The constant mediation from the teacher in and out of class in multimodal ways (e.g., using students' first language to scaffold instructional content, face-to-face tutoring) seemed helpful in clarifying students' confusions or dispelling their frustrations. During the latter half of both the first and second semesters, the students described their progress.

Pin: Now I feel better [...] because of the instructor's guidance over the semester. I now know that some elements [of expository writing] could project more than one dimension of evaluative stance, though in implicit ways. [...] A report word could be an engagement. It could also carry attitude. [...] I did not quite know about this. (IE6)

Min: I almost gave up at times [...] because I was not clear about the theory. [...] I feel my understanding of interpersonal meaning in argumentative writing was enhanced over the semester through interacting with the instructor. (RE7) 
Recall that Min was a stubborn learner who once regarded the theory as being too mechanical. However, through mediation, Min and other students re-galvanized themselves in building their knowledge base and became more determined to engage in the curriculum, constructing reflective selves as language learners at the interpersonal level.

Additionally, their disposition to align with the curriculum was also enhanced by their positive hands-on practices with subcategories (e.g., attitude), as well the overall tenets of the appraisal system, which offered them a new perspective on text deconstruction (i.e., reading). This occurred in the latter half of both expository and argumentative writing, although at that time, their reflective understanding as readers had not been fully extended to their construction practices (i.e., writing).

Min: I do not know everything about the appraisal system and its theory, [...] but I feel it helps me think, [...] just like I have a magnifier. [...] I can see authors' evaluative stances through different ways. (IE7)

Tin: I feel my reading habits are changing, $[\ldots]$ not just relying on my guesses, $[\ldots]$ but focusing on some words [...] and thinking about potential or implicit attitude. [...] There are more explicit evaluative resources in argumentative writing than in expository texts. [...] Practice makes perfect. [...] I feel I can also do better in my own writing. (RE8)

As shown above, students' cognitive worlds were further diversified and enriched because learning the appraisal system provided new practical skills in reading literacy. While their reflective understanding started as a text decoder, students like Tin seemed to be on the way to extending their reflective understanding to writing.

By the end of the each semester, the students' increased reflective understanding could be metaphorized into a battle between their prior assumptions (rule-based grammar learning) and the promoted framework (the co-existence of language resources and meaning in academic literacy) through practices, with the latter dominating students' conceptions as being central learning beliefs. The students reflected on their progress at the end of each semester.

Min: This is a long battle between my previous assumptions/understanding and the appraisal system. This process, I would say, is good but tough. I learned to jump out of intuition and consciously understand the interpersonal meaning and show it in my own argumentative writing. (IE8)

Tin: I am doing [it] with texts or writing. [...] It helps me do something I have never done before. [...] Now I can find more than just grammar. [...] I can link grammar/vocabulary to a specific genre. I feel more interested in [the] appraisal system [...] and feel more confident in more challenging work. (IE9)

In other words, students' reflective understanding was strikingly enhanced through their practices in each semester and over the year and was not limited by their prior 
understanding of academic discourse as de-contextualized understanding. This process was marked by their updated learning beliefs about the usefulness of the appraisal system in navigating interpersonal meaning across the continuum of mode (writing and reading), despite a difficult journey.

\section{Development of Students' Reflective Practice in Reading}

Indeed, students' increased reflective understanding of interpersonal meaning was well mapped to different text type deconstruction. The students' chosen analytic work shown in this section was selected from a time when they reported that they had almost gained enough knowledge, as revealed in their interviews and reflections. On one hand, the students displayed, through their independent analysis, knowledge of the appraisal resources used in expository writing.

Min: When the author described Napoleon's failure in Russia, the author first introduced his early success, and then used two engagement resources, "appear to" and "might," suggesting his potential success in conquering Russia. Apparently, engagement resources acknowledge the potential of some alternative possibilities that might make readers feel comfortable, although the author aligned himself or herself with Napoleon.

Pin: After saying how great Napoleon was, the author used "however," bringing in something different. Following this word, the author used "overlooked" to describe Napoleon's carelessness in knowing Russian weather. The word actually showed the author's sorrow for Napoleon. This was further illuminated by the author's use of an engagement resource-a quote from a famous historian that emphasized that the cold weather was dreadful. That is, the word overlook and a quote both illustrate the author's alignment with Napoleon, although in [these] information texts, it should be objectively reporting cause and effect.

As shown in their analytic work, the students went beyond their previous reading practices of looking at grammar and sentence structure or relying on intuitional guesses (recall students' pre-study survey). While bearing in mind the purpose of expository writing in delivering information, the students located language resources showing how the informational text was infused with the text author's evaluative stance - for example, Min's identification of modulated words (appear, might) used by the text author to maintain text credibility yet project an authorial stance, or Pin's identification of the text author's use of overlook and a quote as a way of implicitly aligning with Napoleon.

On the other hand, students also brought in their understanding of the appraisal system and critically analyzed argumentative texts.

Tin: In the claim, the author explicitly used the verb "manipulate" to show the effects of advertisement on [an] audience. This verb reminds us of the author's explicit attitude toward advertisement. It is different from expository writing, as we did last semester, in that the claim in expository was more implicit, carrying less personal tone. In addition, the 
author used "less often" when she/he said about the lower chance for women to occur in TV advertisements related to the workplace. This is a graduation resource, showing the author's criticism of gender discrimination in TV advertisements.

Min: When providing counter-arguments, the author showed the source of information through "some others" or "these supporters" to remind readers that the information was from them. The authored used "however" to show how he/she shifted stance from counterarguments to his/her own.

As shown in their analytic work, students' identification of engagement resources (e.g., some others, these supporters claim) showed that, as readers, they understood the text author's interaction with the audience as a tactic where the boundary between the external voice from opponents and the author's own position has to be clearly delineated. Similarly, they unearthed explicit appraisal resources, such as attitude (their identification of manipulate) and graduation (their identification of less often), which were linked to the argumentative text's way of manifesting interpersonal meaning. Indeed, their reading practices could be particularly echoed in one of Tin's interview excerpts: "The appraisal system is like a framework for decoding text meanings, facilitating their interaction with text writers, and I feel I am well armed, and I am not a reader with a random guess. I can have my analysis streamlined" (IE10).

\section{Reflective Learning as Illuminated in Writing Practices}

The students' writing practices seemed to encounter a slower and tougher progression than reading at the interpersonal level, consistent with their reflective understanding (see early sections). The students' successful independent deconstruction of sample texts did not immediately transfer to their writing. In early writings, the students tended to have personal comments in places where they were supposed to provide facts (field notes). The slower progress manifested obviously in Tin's reflection: "I had focused on attitude as [a reader], but I did not quite behave very cautiously in my writing, I think because my writing knowledge was not mature enough" (RE9). Indeed, it could be because writing development involves a greater cognitive load (Stotsky, 1983). It was not until after rounds of mediation (in and out of class) with the teacher that the students became able to regulate their writing by the latter half of each semester and achieve understanding of interpersonal meaning for the specific text type.

Attitude. In the category of attitude, students initially could not output an attitude germane to expository writing, where the genre expects an objective tone and implicit attitude, although students had been familiar with this as readers at the time.

Min: Global warming has a disastrous influence on the coastal areas ... [evidence omitted]. Therefore, thousands of cities including some developed areas around the world will vanish because of global warming. (Initial writing excerpt) 
Min's use of will vanish carries a strong personal attitude that was not favored here. Indeed, as the summary part of the paragraph, readers do not expect anything new like personal comments (Schleppegrell, 2001). With the instructor's implicit feedback and efforts in connecting her previous reading practices, Min changed the last sentence into a new version: Therefore, these coastal areas, as a result of global warming, are now apparently in peril. Min reworded her summary in a more objective tone, and she used apparently to project a less obvious attitude toward the threat of global warming to coastal areas. Her modification showed better mastery of attitude as a creator of expository writing.

A similar scenario related to argumentative writing also occurred. While students as readers had located the explicit use of attitude in argumentative texts, they seemed over-expressive of attitude in their writing.

Pin: Standardized testing is a reliable means to identify the academic performance of students ... [evidence omitted]. Hence, standardized testing is [an] objective measurement of student achievement. (Initial writing excerpt)

Comparing Pin's claim, evidence, and summary, she used objective in the summary sentence to indicate the value of standardized testing; however, this was not mentioned in the claim or evidence. With mediation on the relationship between the sub-claim and the relevant evidence, Pin replaced objective with the appropriate attitudinal and hidden lexis useful. Pin's later version read: Hence, standardized testing is a useful measurement of student achievement.

Engagement. For expository writing, practices were improved, as illustrated by students' control of modal verbs or quantifiers to enhance the reliability of the facts they presented.

Pin: In high schools in China, students are dominated by study and exams, and the ultimate mission for them is to achieve a high score. (Initial writing excerpt)

Following mediation on the function of modal verbs or other words, as well as the background of high school in China (where not every school is test-oriented), Pin then made revisions, using many and may be to soften her tone: In high schools in China, many students are dominated by study and exams, and the ultimate mission for them may be to achieve a high score.

In contrast, in argumentative writing, students initially had trouble effectively engaging readers by posting signposts when countering opponents' arguments, although in reading, students had clear knowledge of this.

Min: Some argue there is an assured link between playing violent video games and increased levels of criminal behavior. According to [researcher name omitted] research... (Initial writing excerpt) 
With mediation, Min later changed according to into a noun phrase: Evidence often used by supporters of this claim is... This clearly demonstrated the side this research study was aligned with. The category of engagement helped student writers clearly show to readers what the information was, where it was from, and more importantly, the disintegration of this research from the author's own position.

Graduation. This construct offered students the ability to graduate their information by showing readers the semantic strength/typicality of the information.

Tin: In high school, merely memorizing textbook content and teachers' instruction is enough for students to cope with tests. In college, however, students need to learn as much as possible in order to achieve high grades. (Initial writing excerpt)

The student deleted the intensifier merely, as this was an obviously over-generalized fact, and replaced it with an engagement resource, may be, to weaken the semantic intensity: In high school, memorizing textbook content and teachers' instruction may be enough for students to cope with tests... This made the support more reliable and convincing for the purpose of supporting her claim on the difference between college and high school education.

Similarly, in argumentative writing, students sometimes were lost in terms of using intensifiers between their evidence and their interpretation.

Tin: Drinking milk exposes adults to higher risks of heart disease ... [evidence omitted]. The two pieces of evidence above all indicates that milk consumption brings severe diseases nearer to adults. (Initial writing excerpt)

The student initially used severe to show the negative effect of milk, even though the evidence was very carefully modulated and only demonstrated the close relation between drinking milk and health. Through the instructor's minimal prompt, Tin replaced this word with high, showing appropriate semantic load/intensity based on the relationship between the claim and the evidence available: The two pieces of evidence above both indicate a high possibility for milk consumers to have diseases.

In summary, students' reflective understanding of interpersonal meaning gained through exposure to appraisal system-based teaching was also externally displayed in decoding or constructing the relationship between linguistic resources and interpersonal meaning for different generic purposes. Though not in a simultaneous way (with writing development occurring later than reading practice) and not in a fully professional manner, students ultimately demonstrated being able to regulate interpersonal meaning for diverse genres (expository and argumentative writing) as either readers or writers. Additionally, it should be noted that their reflective practice development fed into itself (between understanding and practices) and was particularly expedited by their teacher's efforts over this long journey. 


\section{Discussion}

Obviously, the findings in this case study can only be carefully extended to similar contexts where EFL students learn English in a de-contextualized way and have relatively similar language proficiency. Nevertheless, this small-scale study has three illuminating findings important to relevant contexts. First, developing students' reflective practices in language learning as a meaning-making process is helpful in activating EFL students' agency, challenging their past selves, and transitioning them to active selves who can critically understand and construct or deconstruct discourse. As shown in this study, the students initially had limited knowledge and constrained practices because of a lack of effective instructional exposure. In this reflection-based curriculum, the students were constantly prompted to ruminate over their reading and writing as a meaning-making process and gradually challenged themselves to develop their new professional selves as academic writers and readers through the processes of writing and reading. This finding resonates with previous studies (Larrivee, 2000; Park, 2003) that illustrated the power of reflection-based instruction in emancipating participants from the shackles of constrained teaching practices (e.g., teacher-dominated instruction).

This study particularly and empirically highlights how EFL students were motivated to reflect upon diverse layers of language as informed by an SFL perspectivethrough context, meaning-making, and linguistic choices (cf. Hasan, 2005). This helped students gain a holistic knowledge of academic myths and enabled them to effectively and critically participate in discourse construction or deconstruction. This finding contrasts sharply with reflection-based teaching in EFL contexts where attention was focused on macro strategies or general conceptual comprehension, such as challenging instructors in terms of text content or understanding different genres in writing and reading classrooms (cf. DeWaelsche, 2015; Lee, 2007).

Moreover, with an explicit teaching of the appraisal system, the students gradually gained an enhanced understanding of interpersonal meaning as readers and authors in expository and argumentative writing, although their new conceptualization of writing seemed slower than reading in each semester, likely due to the natural trajectory of learners' development (Stotsky, 1983). In this regard, the study further empirically illuminates how the appraisal system in EFL contexts is a crucial component in expediting students' cognitive changes at the linguistic level. This study, among the few studies in EFL contexts, joined research from ESL contexts (Harman \& Simmons, 2014; O'Hallaron et al., 2015) and illuminated how appraisal system-based instruction contributed to EFL students' reflective understanding as both readers and writers. The students' improved understanding of academic literacy complemented our understanding that EFL students' unsatisfactory performance could be attributed to ineffective teaching and could be improved once appropriately guided in an effective curriculum, such as an SFL-based system (cf. Zhang, 2017). 
Finally, this study shows that students' reflective understanding at the interpersonal level was externally demonstrated by EFL students' successful interpretation and construction of interpersonal meaning in literacy practices, which in turn enhanced their reflective understanding. After tracking students over one academic year, it should be noted that students' reflective understanding seemed to follow a non-linear trajectory; familiarity with one genre (the first semester's expository writing) might not guarantee success with another genre (the second semester's argumentative writing). Given specific linguistic features related to each genre, it was understandable that students might require additional efforts in understanding a different genre (Harman, 2017). Their literacy practices, similar to their reflective understanding of writing and reading, also developed at different paces; writing practices developed slower. This was possibly because practices were driven by students' understanding, in conjunction with the natural learning trajectory (Stotsky, 1983; Zhang, 2017). The complex adjustment process in connecting their understanding and practices illuminated students' nuanced emotional engagement or hurdles occurring in appraisal-based curriculum, which has not been given sufficient attention in either ESL (cf. Harman, 2017; Rose \& Martin, 2012) or EFL contexts (e.g., Yasuda, 2017). Indeed, while not limited to teacherstudent interaction and students' use of the appraisal system in reading or writing (cf. Harman \& Simmons, 2014), this year-long study uniquely illuminates how students' understanding of academic literacy, emotional constraints, mediation, and their writing/reading practices interacted with each other. Their emotional discomfort in approximating the linguistic knowledge needed for reflective understanding was mitigated by teacher mediation; their approximated knowledge benefited and was enhanced through their practices. The whole complex trajectory revealed through this longitudinal study furthers our understanding of the role of the appraisal system in the process of fostering EFL students' reflective practices.

\section{Conclusions and Implications}

This study contributes to the repertoire of fostering reflective EFL learners by highlighting an SFL-based appraisal system as the teaching praxis. Also, through a longitudinal tracking of students in two different writing classrooms, it uniquely points out the complexity of adjusting to different genres of academic discourse and the challenges that emerge in this process, which nevertheless can be mitigated by teacher mediation.

The implications of the study include the following five aspects. First, in developing EFL learners' reflective practices - apart from training their general reflective ability, such as by questioning instructional content (e.g., DeWaelsche, 2015) - teachers should be aware of the interaction between linguistic choices and contextualized meaning in academic discourse and teach accordingly so as to better help students become reflective learners. Second, the findings of this study are not necessarily 
limited to language learners; teachers in other disciplines (e.g., mathematics, science) could adopt similar instructional strategies, focus on the appraisal system and meaning-making, and help students better navigate these school subjects at an interpersonal level. Third, students may face emotional challenges in adjusting to a new curriculum that is totally different from what they previously experienced. Teachers should be cognizant of this and provide not only support through offering effective meta-linguistic knowledge in class but also after-class scaffolding if necessary. Fourth, the teacher is the key to the students' success, which means that teacher education programs are important. As Gebhard (2010) noted, merely offering macro learning strategies (e.g., sentence structure or text structure) would not be so helpful in changing times, where knowledge of contextually appropriate language choices is closely related to students' success with academic literacy. Thus, education policy makers in EFL contexts or similar backgrounds should be aware of SFL as a training tool and promote pertinent education training programs. For example, EFL teachers could become reflective through exposure to SFL-based education before their implementation of a similar curriculum in their own classrooms. Finally, given the different pace of development in students' reading and writing literacy, teachers may have to be patient and give ample time for students to practice reading and writing, especially when writing tends to lag behind reading development. Therefore, in enacting a similar curriculum, teachers, with appropriate mediation (e.g., feedback), should constantly encourage students to apply their newly gained knowledge to practices and refine their knowledge base.

Future studies could be conducted in similar EFL contexts at different educational levels (e.g., secondary language education). Most importantly, another two dimensions of SFL-ideational meaning (the core content of discourse activities) and textual meaning (the way of organizing discourse), as well as their linguistic manifestationscould also be harnessed to investigate their effects on students' reflective practices.

\section{References}

Attride-Stirling, J. (2001). Thematic networks: An analytic tool for qualitative research. Qualitative Research, 1(3), 385-405.

Bayat, N. (2014). The effect of the process writing approach on writing success and anxiety. Educational Sciences: Theory and Practice, 14(3), 1133-1141.

DeWaelsche, S. A. (2015). Critical thinking, questioning and student engagement in Korean university English courses. Linguistics and Education, 32, 131-147.

Dewey, J. (1933). How we think: A restatement of the relation of reflective thinking to the educative process. Chicago, IL: Henry Regnery.

Gebhard, M. (2010). Teacher education in changing times: A systemic functional linguistics (SFL) perspective. TESOL Quarterly, 44(4), 797-803. 
Harklau, L. (2000). From the "good kids" to the "worst": Representations of English language learners across educational settings. TESOL Quarterly, 34(1), 35-67.

Harman, R. (2017). Bilingual learners and social equity: Critical approaches to systemic functional linguistics. New York, NY: Springer.

Harman, R., \& Simmons, A. (2014). Critical systemic functional linguistics and literary narratives in subject English: Promoting language awareness and social action among K-12 students. In L.C. De Oliveira \& J. G. Iddings (Eds.), Genre pedagogy across the curriculum: Theory and application in U.S. classrooms and contexts (pp. 75-91). London, UK: Equinox Publishers.

Hasan, R. (2005). Semiotic mediation, language and society: Three exotropic theories: Vygotsky, Halliday and Bernstein. In J. Webster (Ed.), Language, society and consciousness. The collected works of Ruqaiya Hasan (vol. 1, pp. 130-156). London, UK: Equinox.

Larrivee, B. (2000). Transforming teaching practice: Becoming the critically reflective teacher. Reflective Practice, 1(3), 293-307.

Lee, I. (2007). Assessment for learning: Integrating assessment, teaching, and learning in the ESL/ EFL writing classroom. Canadian Modern Language Review, 64(1), 199-213.

Macken-Horarik, M., Love, K., \& Unsworth, L. (2011). A grammatics 'good enough' for school English in the 21st century: Four challenges in realizing the potential. Australian Journal of Language and Literacy, 34(1), 9-23

Martin, J. R., \& White, P. R. (2003). The language of evaluation. Basingstoke: Palgrave Macmillan.

O’Hallaron, C. L., Palincsar, A. S., \& Schleppegrell, M. J. (2015). Reading science: Using systemic functional linguistics to support critical language awareness. Linguistics and Education, 32, 55-67.

O'Hallaron, C. L., \& Schleppegrell, M. J. (2016). "Voice” in children's science arguments: Aligning assessment criteria with genre and discipline. Assessing Writing, 30, 63-73.

Park, C. (2003). Engaging students in the learning process: The learning journal. Journal of Geography in Higher Education, 27(2), 183-199.

Rose, D., \& Martin, J. R. (2012). Learning to write, reading to learn: Genre, knowledge and pedagogy in the Sydney school. London, UK: Equinox.

Russell, T. (2005). Can reflective practice be taught? Reflective Practice, 6, 199-204.

Schleppegrell, M. J. (2001). Linguistic features of the language of schooling. Linguistics and Education, 12(4), 431-459.

Stotsky, S. (1983). Research on reading/writing relationships: A synthesis and suggested directions. Language Arts, 60(5), 627-642.

Symons, C., Palincsar, A. S., \& Schleppegrell, M. J. (2017). Fourth-grade emergent bilinguals' uses of functional grammar analysis to talk about text. Learning and Instruction, 52, 102-111.

Yasuda, S. (2017). Toward a Framework for Linking Linguistic Knowledge and Writing Expertise: Interplay Between SFL-Based Genre Pedagogy and Task-Based Language Teaching. TESOL Quarterly, 51(3), 576-606.

Zhang, X. (2017). Exploring a novice Chinese EFL teacher's writing beliefs and practices: A systemic functional perspective. International Journal of Language Studies, 11(1), 95-118. 